\title{
EDITORIAL \\ CAR-T cells: the narrow path between hope and bankruptcy?
}

Bone Marrow Transplantation (2017) 52, 1588-1589; doi:10.1038/ bmt.2017.241

The announcement in late August that the US Food and Drug Administration (FDA) approved Kymriah (tisagenlecleucel), ${ }^{1}$ an autologous chimeric antigen receptor (CAR) T-cell suspension targeting CD19 malignancies, raises tremendous hopes as well as uncertainties in patients and the medical community. Tisagenlecleucel is the first of its kind to reach the market, although the European Medicines Agency (EMA) and FDA have approved other types of human cell-based therapies in the past. As most previously authorized cell and gene therapies were met with little commercial success thus far, all stakeholders will scrutinize the fate of the newcomer.

Over the past 5 years, clinical evidence has accumulated showing that genetically engineered autologous or allogeneic T cells expressing a CAR can exert potent and durable antitumour activity in severely ill patients affected with advanced CD19 ${ }^{+}$ lymphoid malignancies, including recipients of allogeneic hematopoietic cell transplantation who relapsed post transplant. ${ }^{2-8}$ In addition, an increasing body of evidence suggests that CAR-T cells can also be effective when targeting other tumour antigens expressed on other categories of blood malignancies, such as B-cell maturation antigen in multiple myeloma. ${ }^{9}$

Autologous CAR-T cells are a true example of 'personalized medicine' as each medicinal product is prepared for a designated recipient. This is typically how hematopoietic cell transplants have been delivered over the past 60 years, based on an organization that largely involves local networks of expertise associating professionals experienced in specific clinical care, cell collection and cell-processing activities. Although the concept of central manufacturing of medicinal products, manufactured by pharma companies from a unique and variable apheresis product collected at an academic facility, initially raised some scepticism, studies such as the ZUMA-1 trial have unequivocally demonstrated that logistical issues could be resolved, ${ }^{10}$ at least to the extent that academic centres meet certain standards in terms of cumulated expertise, organization and quality management. Whether central manufacturing will be financially sustainable remains to be demonstrated, as in the absence of batch manufacturing, there is little room for cost reduction associated with mass production as can be seen for conventional drugs.

Early reports of these exciting results reflect the sustained commitment and collaboration of high-profile academic institutions based in the United States of America with biotech or pharma industry, paving the way for marketing authorization and commercialization. As expected, the first marketing authorization was delivered by the US competent authority. Surveys of ongoing clinical trials designed to evaluate CAR-T cells for various indications-now entering the field of solid tumours-show sustained activity in north America and in Asia, with research groups and commercial companies exploring new indications, new targets on tumour cells, new designs for CAR and new ways to genetically modify $T$ cells, allowing for highly versatile technology and seemingly endless avenues to optimize clinical applications.

Through the publication of the 2007 regulation on advanced therapy medicinal products ${ }^{11}$ Europe had designed a regulatory framework for this new category of medicinal products (CAR-
T cells will fall into the subcategory of 'gene therapy medicinal products'). Although the regulation appeared as a smart and most welcome anticipation of an evolving field when it was released, it has so far largely failed to meet one of its objectives, that is, to accelerate or facilitate access of these innovative therapeutic options to European citizens. Indeed, clinical activity in the field of CAR-T cells remains relatively modest across member states and neighbouring countries, ${ }^{12}$ with many academic centres waiting for approval of their participation as co-investigators in industrysponsored trials, and relatively few biotech companies originating from the scientific community established on our continent.

Access of European patients to CAR-T cell therapy is unlikely to improve when the Committee for Human Medicinal Products delivers the first positive opinions and EMA approves the first CAR$T$ cell therapies. Following FDA approval, Novartis announced a price tag in the range of 475000 US\$ for Kymriah. This does not include the cost of patient care in the weeks following administration, including those of lympho-depleting chemotherapy, and the management of potentially severe complications, such as cytokine release syndrome or neurological toxicities, ${ }^{13}$ that may add up 150 000-200 000 US\$ on top of the drug price. The price is way above the cost of an allogeneic transplantation in European countries, way above the already inflated price for immune checkpoint inhibitors and likely represents more than the average lifetime household assets in most developed countries, not to mention low-to-middle-income countries. A growing number of reports were recently published looking at costs of newly developed drugs, drug combinations and the financial burden for patients as well as globally. ${ }^{14,15}$ Negotiations between CAR-T cell manufacturers and health-care payers are likely to be harsh and lengthy and will inevitably lead to more or less stringent restrictions and delayed access for patients who are in immediate need. In this context, careful selection of candidate patients and accurate clinical and biological monitoring of efficacy and toxicities are required to avoid wasting resources. Moreover, postmarketing long-term follow-up of recipients in which these living drugs persist for extended periods of time is likely to be mandatory. The transplant community handling complex procedures on a daily basis is well prepared to meet these challenges. It relies on strong interactions across different fields of expertise as needed to oversee all aspects of CAR-T cell administration. Indeed this community has built a culture of quality assurance, selfreporting and evaluating efficacy and side effects associated with the constant flow of innovations that were introduced in the field of hematopoietic cell transplantation over the past 60 years. The EBMT registry-containing data on more than half a million transplant cases-serves as a model for other medical disciplines as also recognized by authorities, such as EMA. ${ }^{16}$ Finally, the transplant community was a pioneer in deploying quality management to foster excellence and promote harmonization in the delivery of a complex therapeutic procedure, as exemplified by the accreditation process that demonstrates compliance of transplant programmes with the FACT-JACIE International Standards for Hematopoietic Cellular Therapies. Indeed, the FDA and the manufacturer of tisagenlecleucel have warned that Kymriah would only be available at selected centres registered with the competent authority; criteria to identify these centres are likely to include all or most of the above characteristics and must take into account the needs to satisfy both adult and paediatric needs. 
The introduction of CAR-T cells may represent a true revolution for some patients affected with severe or poor prognosis malignant diseases. However, a number of obstacles need to be overcome before these personalized therapies deliver their full promises. ${ }^{17}$ Predicting efficacy, managing toxicities, identifying organizational and technical solutions to lower costs, promoting original reimbursement solutions through discussions with manufacturers, regulators, payers and patients associations, maintaining the capacity of the academic sector to pursue relevant preclinical and clinical research in the field will all be needed to improve accessibility and affordability. This new era will also require open and ongoing dialogue between authorities and health-care experts to ensure well-informed discussions. The transplant community is well prepared to deal with such issues by taking advantage of its long-standing and multidisciplinary experience. It should see this extraordinary challenge as a way to rejuvenate the cellular therapy field.

\section{CONFLICT OF INTEREST}

$C B$ is an inventor on different patents on cancer immunotherapy and received research support from Molmed spa and Intellia Therapeutics. JK is an inventor on different patents with $\gamma \delta T C R$ sequences, recognition mechanisms and isolation strategies, CSO and shareholder of Gadeta (www.gadeta.nl). JK has received research support from Miltenyi Biotech and Gadeta. The remaining authors declare no conflict of interest.

C Chabannon ${ }^{1}$, J Kuball ${ }^{2}$, E Mcgrath ${ }^{3}, \mathrm{P} \mathrm{Bader}^{4}, \mathrm{C}$ Dufour ${ }^{5}$, A Lankester ${ }^{6}$, GW Basak ${ }^{7}$, S Montoto $^{8}$, A Nagler $^{9}$, JA S Snowden $^{10}$, J Styczynski ${ }^{11}$, RF Duarte ${ }^{12}, \mathrm{~N} \mathrm{Kröger}^{13}$ and M Mohty ${ }^{14}$ on behalf of the European Society for Blood and Marrow

Transplantation (EBMT)

${ }^{1}$ Institut Paoli-Calmettes, Inserm CBT-1409 \& Aix-Marseille Université, Marseille, France;

${ }^{2}$ Laboratory of Translational Immunology \& Department of Hematology, UMC Utrecht, Utrecht, The Netherlands; ${ }^{3}$ EBMT Legal \& Regulatory Affairs Committee of EBMT, Barcelona, Spain;

${ }^{4}$ Division for Stem Cell Transplantation and Immunology, Department for Children and Adolescents, University Hospital, Goethe University, Frankfurt/Main, Germany; ${ }^{5}$ Hematology Unit, G. Gaslini, Research Children's Hospital, Genova, Italy;

${ }^{6}$ Department of Pediatrics, Division of Stem Cell Transplantation, Leiden University Medical Center, Leiden, The Netherlands;

${ }^{7}$ Department of Hematology, Oncology and Internal Medicine, Medical University of Warsaw, Warsaw, Poland;

${ }^{8}$ Haemato-oncology, St Bartholomew's Hospital, Barts Health NHS Trust, London, UK; ${ }^{9}$ Hematology Division, Chaim Sheba Medical Center, Tel Hashomer, Israel; ${ }^{10}$ Department of Haematology, Sheffield Teaching Hospitals NHS Foundation Trust, Sheffield, UK; ${ }^{11}$ Department of Pediatric Hematology and Oncology; Collegium Medicum; Nicolaus Copernicus University Torun, Bydgoszcz, Poland;

${ }^{12}$ Hospital Puerta de Hierro - Universidad Autónoma de Madrid, Madrid, Spain;
${ }^{13}$ Department of Stem Cell Transplantation, University Hospital Eppendorf, Hamburg, Germany and

${ }^{14}$ Hôpital Saint-Antoine, Université Pierre \& Marie Curie and INSERM, Paris, France

E-mail: chabannonc@ipc.unicancer.fr or thercell@ipc.unicancer.fr

\section{REFERENCES}

1 Roselli EA, Mezzadra R, Frittoli MC, Maruggi G, Biral E, Mavilio F et al. Correction of beta-thalassemia major by gene transfer in haematopoietic progenitors of pediatric patients. EMBO Mol Med 2010; 2: 315-328.

2 Maude SL, Frey N, Shaw PA, Aplenc R, Barrett DM, Bunin NJ et al. Chimeric antigen receptor T cells for sustained remissions in leukemia. N Engl J Med 2014; 371: 1507-1517.

3 Kochenderfer JN, Dudley ME, Kassim SH, Somerville RP, Carpenter RO, Stetler-Stevenson $\mathrm{M}$ et al. Chemotherapy-refractory diffuse large B-cell lymphoma and indolent B-cell malignancies can be effectively treated with autologous T cells expressing an anti-CD19 chimeric antigen receptor. J Clin Oncol 2015; 33: 540-549.

4 Lee DW, Kochenderfer JN, Stetler-Stevenson M, Cui YK, Delbrook C, Feldman SA et al. T cells expressing CD19 chimeric antigen receptors for acute lymphoblastic leukaemia in children and young adults: a phase 1 dose-escalation trial. Lancet 2015; 385: 517-528.

5 Porter DL, Hwang WT, Frey NV, Lacey SF, Shaw PA, Loren AW et al. Chimeric antigen receptor $\mathrm{T}$ cells persist and induce sustained remissions in relapsed refractory chronic lymphocytic leukemia. Sci Transl Med 2015; 7: 303ra139.

6 Turtle CJ, Hanafi LA, Berger C, Gooley TA, Cherian S, Hudecek M et al. CD19 CAR-T cells of defined CD4+:CD8+ composition in adult B cell ALL patients. J Clin Invest 2016; 126: 2123-2138.

7 Brudno JN, Somerville RP, Shi V, Rose JJ, Halverson DC, Fowler DH et al. Allogeneic T cells that express an anti-CD19 chimeric antigen receptor induce remissions of B-cell malignancies that progress after allogeneic hematopoietic stem-cell transplantation without causing graft-versus-host disease. J Clin Oncol 2016; 34: 1112-1121.

8 Garfall AL, Maus MV, Hwang WT, Lacey SF, Mahnke YD, Melenhorst JJ et al. Chimeric antigen receptor T cells against CD19 for multiple myeloma. $N$ Engl J Med 2015; 373: 1040-1047.

9 Sending CAR T cells after multiple myeloma. Cancer Discov (e-pub ahead of print 8 August 2017; doi:10.1158/2159-8290.CD-NB2017-088).

10 Locke FL, Neelapu SS, Bartlett NL, Siddiqi T, Chavez JC, Hosing CM et al. Phase 1 results of ZUMA-1: a multicenter study of KTE-C19 anti-CD19 CAR T cell therapy in refractory aggressive lymphoma. Mol Ther 2017; 25: 285-295.

11 Regulation (EC) No 1394/2007 of The European Parliament and of The Council of 13 November 2007 on advanced therapy medicinal products and amending Directive 2001/83/EC and Regulation (EC) No 726/2004. 2007.

12 Hartmann J, Schussler-Lenz M, Bondanza A, Buchholz CJ. Clinical development of CAR T cells-challenges and opportunities in translating innovative treatment concepts. EMBO Mol Med 2017; 9: 1183-1197.

13 Brudno JN, Kochenderfer JN. Toxicities of chimeric antigen receptor T cells: recognition and management. Blood 2016; 127: 3321-3330.

14 Huntington SF, Weiss BM, Vogl DT, Cohen AD, Garfall AL, Mangan PA et al. Financial toxicity in insured patients with multiple myeloma: a cross-sectional pilot study. Lancet Haematol 2015; 2: e408-e416.

15 Zafar SY, Newcomer LN, McCarthy J, Fuld Nasso S, Saltz LB. How should we intervene on the financial toxicity of cancer care? One shot, four perspectives. Am Soc Clin Oncol Educ Book 2017; 37: 35-39.

16 European Medicines Agency. Observations and recommendations arising from the workshop. In: Inspections, Human Medicines, Pharmacovigilance and Committees Division (ed.), Patient Registries Workshop, 28 October 2016, 2017.

17 Bach PB, Giralt SA, Saltz LB. FDA approval of tisagenlecleucel. Promise and complexities of a $\$ 475000$ cancer drug. JAMA (e-pub ahead of print 20 September 2017; doi:10.1001/jama.2017.15218). 